\title{
ADAPTIVE SINGULAR VALUE DECOMPOSITION FILTERING TO ENHANCE REFLECTORS AND GEOLOGICAL STRUCTURES IN 3D SEISMIC DATA
}

\author{
Washington Oliveira Martins ${ }^{1}$, Milton José Porsani² and Michelângelo G. da Silva ${ }^{2}$
}

\begin{abstract}
We applied an adaptive seismic data filtering method, based on the singular value decomposition (SVD) to improve the identification of reflectors and geological structures in 3D stacked seismic volumes. This was done using the SVD method to perform the decomposition of the seismic data matrix in eigenimages. SVD filtering can be seen as a multichannel filtering method where each filtered seismic trace retains the coherence of neighboring seismic traces. For the filtering of a 3D volume, we use a matrix operator formed with five adjacent traces of the original volume. At each position of the filter operator, the filtered trace was obtained by taking the central trace of the first eigenimage. Thus, we reinforce the lateral coherence corresponding to the primary reflections. This filtering technique relies on the property of the SVD method in which eigenimage associated with the highest single values retains the part of the greater spatial correlation associated to the seismic reflectors. The proposed SVD filtering method was applied to a 3D volume of synthetic seismic data. The results were compared with those obtained using the conventional FX deconvolution method. The results demonstrate the efficacy of the SVD approach both in improving spatial coherence of reflections and in noise attenuation.
\end{abstract}

Keywords: seismic data processing, SVD filtering, 3D pos-stacked filtering, adaptive filtering.

RESUMO. Nós aplicamos um método de filtragem adaptativa de dados sísmicos, baseado na decomposiçã̃o em valores singulares (SVD), para melhorar a identificação de refletores e estruturas geológicas em volumes sísmicos empilhados 3D. Isto foi feito usando o método SVD para realizar a decomposiç̧ão da matriz de dados sísmicos em autoimagens. A filtragem SVD pode ser vista como um método de filtragem multicanal onde cada traço sísmico filtrado retém a coerência dos traços sísmicos vizinhos. Para a filtragem de um volume 3D, utilizamos um operador matricial formado com cinco traços adjacentes a cada traço sísmico do volume original. Em cada posição do operador, o traço filtrado foi obtido tomando o traço central da primeira auto-imagem. Assim, reforçamos a coerência lateral correspondente às reflexões primárias. Esta técnica de filtragem se vale da propriedade do método SVD no qual a autoimagem associada aos maiores valores singulares retém a parte de maior correlação espacial, associada aos refletores sísmicos. 0 método de filtragem proposto SVD foi aplicado a um volume 3D de dados sísmicos sintéticos. Os resultados foram comparados com os obtidos utilizando o método convencional de deconvolução FX. Os resultados demonstram a eficácia da abordagem SVD tanto na melhoria da coerência espacial das reflexões quanto na atenuação do ruído.

Palavras-chave: processamento sísmico, filtragem SVD, filtragem pós-stack 3D, filtragem adaptativa.

\footnotetext{
1 Petróleo Brasileiro S.A. - PETROBRAS, Av. Antônio Carlos Magalhães, 1113, Itaigara, Salvador, BA, Brazil - E-mail: womartins7@yahoo.com.br

2 Universidade Federal da Bahia, Centro de Pesquisa em Geofísica e Geologia, Instituto de Geociências, \& INCT-GP/CNPq/Brazil, Campus Universitário da Federação Salvador, Salvador, BA, Brazil - E-mails: porsani@cpgg.ufba.br; mgs@cpgg.ufba.br
} 


\section{INTRODUCTION}

In the petroleum industry the activity of interpretation of seismic data is fundamental, since the exploratory risk associated to this activity depends strongly on the quality of the seismic section. We soon notice the importance of the role of the processing geophysicist in the development of new filtering methods with the purpose of increasing the signal-to-noise ratio to obtain a better quality seismic image that is representative of the geological reality to be investigated. The functionality of the interpretation tools and the extraction of seismic attributes are strongly dependent on the data quality, either for structural or stratigraphic interpretation. As an alternative in the search to prepare the stacked data to enable the application of the interpretation techniques, and to reduce the problems of low quality of the sections due to the low signal-to-noise ratio, we present an application of the SVD adaptive filtering in a 3D seismic volume to highlight reflectors and geological structures.

Many different filtering methods have been used to improve signal-to-noise ratio of the seismic data. The FX deconvolution is applied in the frequency $\times$ space domain, thus allowing the reduction of the random noise, and improving coherence (Gulunay, 1986). The SVD filtering can be used to enhance the spatial coherence of seismic data, making reflections more evident, and at the same time attenuating non-coherent noise. This SVD filtering technique has been implemented and applied in various types of seismic data processing problems. Freire \& UIrych (1988) applied SVD filtering to separate the up and down wave fields of seismic profiling (VSP). Porsani et al. (2009) used SVD filtering to attenuate ground-roll in earthquake data. Bekara \& Baan (2007) proposed a local SVD approach to noise suppression. Kendall (2005) proposed the use of the SVD method to obtain polarization filters for attenuation of ground-roll in multicomponent data. Karsli (2008) proposed the use of Wiener filters to estimate ground-roll through linear (or non-linear) reference noise, corresponding to sweep generated in the groundroll. Chiu \& Howell (2008) proposed the method that uses SVD to generate eigenimages that represent coherent noise in a given window in the space-time domain. The data inside windows are transformed into the analytical signal and the complex SVD decomposition is obtained by extracting eigenimages from the coherent part of the noise. Tyapkin (2003) proposed using the event alignment method to make horizontal noise in one or more sections of the common-point seismograms. In each section coherent noise (ground-roll) is preserved in the first eigenimages. The other eigenimages represent the signal and this part is transformed back into the space-time domain.
SVD filtering in the form used by Porsani et al. (2010a, 2010b) operates with the SVD decomposition of a subset of traces extracted from a 2D seismic line or 3D seismic volume. Only a trace of the interior of the moving window (2D or 3D) associated with the first eigenimages is chosen to represent the filtered trace. SVD filtering can be seen as a multichannel filtering method where each filtered trace maintains a certain degree of coherence with the immediately neighboring traces. This filtering technique preserves the relations of amplitude, phase and spatial correlation of the seismic events, while allowing the elimination of the incoherent noise, usually associated to the last eigenvalues.

In this paper we apply SVD filtering to synthetic data corresponding to a maritime $3 \mathrm{D}$ volume, comparing the results of SVD and FX-deconvolution filtering. The obtained results show the effectiveness of the SVD method, both in improving the spatial coherence of the reflections and also in the attenuation of uncorrelated noise, increasing the signal-to-noise ratio and thus revealing the features and geological structures present in the sections.

\section{SVD FILTERING}

Considering the subset of $M$ seismic traces selected from a 2D seismic section or a given 3D seismic volume, $d\left(t_{i}, x_{j}\right), i=$ $1, \ldots M$ and $j=1, \ldots N$. The data matrix, $\mathbf{D}=$ $\left[\mathbf{d}_{1}, \ldots, \mathbf{d}_{N}\right]=\left\{d\left(t_{i}, x_{1}\right), \ldots, d\left(t_{M}, x_{N}\right)\right\}$ can be decomposed through of the SVD method as shown below (Golub \& Van Loan, 1996).

$$
\mathbf{D}=\mathbf{U} \Sigma \mathbf{V}^{T}
$$

where $\mathbf{U}$ and $\mathbf{V}$ are orthonormal matrices such that $\mathbf{U}^{-1}=$ $\mathbf{U}^{T}$ and $\mathbf{V}^{-1}=\mathbf{V}^{T}$. The SVD in reduced form may be represented as:

$$
\begin{aligned}
& \boldsymbol{\Sigma}=\operatorname{diag}\left\{\sigma_{1}, \ldots, \sigma_{N}\right\} \text { matrix of singular values } \\
& (N \times N), \sigma_{1} \geq \sigma_{2} \geq \cdots \geq \sigma_{N} \geq 0 ; \\
& \mathbf{U}=\left[\mathbf{u}_{1} \cdots \mathbf{u}_{N}\right] \text { matrix of eigenvectors }(M \times N) \\
& \text { corresponding to variable } t ; \\
& \mathbf{V}=\left[\mathbf{v}_{1} \cdots \mathbf{v}_{N}\right] \text { matrix of eigenvectors }(N \times N) \text { cor- } \\
& \text { responding to variable } x \text {. }
\end{aligned}
$$

Using $\widetilde{\mathbf{U}}=\mathbf{U} \Sigma=\left[\sigma_{1} \mathbf{u}_{1} \ldots \sigma_{M} \mathbf{u}_{M}\right]$ one may rewrite Eq. (1) as,

$$
\begin{aligned}
\mathbf{D} & =\left[\mathbf{d}_{1} \cdots \mathbf{d}_{j} \cdots \mathbf{d}_{N}\right]=\widetilde{\mathbf{U}} \mathbf{V}^{T} \\
& =\left[\sigma_{1} \mathbf{u}_{1} \cdots \sigma_{N} \mathbf{u}_{N}\right]\left[\begin{array}{c}
\mathbf{v}_{1}^{T} \\
\vdots \\
\mathbf{v}_{N}^{T}
\end{array}\right]
\end{aligned}
$$


From where we get the equation for SVD decomposition of a trace of the subset of $N$ traces of the original section.

$$
\begin{aligned}
\mathbf{d}_{j} & =\left[\sigma_{1} \mathbf{u}_{1} \ldots \sigma_{N} \mathbf{u}_{N}\right]\left[\begin{array}{c}
v_{1, j} \\
\vdots \\
v_{N, j}
\end{array}\right] \\
& =\widehat{\mathbf{d}}^{j}{ }_{1}+\cdots+\widehat{\mathbf{d}}^{j}{ }_{k}+\cdots+{\widehat{\mathbf{d}^{j}}}_{N} \\
& =\sum_{k=1}^{N} \sigma_{k} \mathbf{u}_{k} v_{k, j}
\end{aligned}
$$

Note that the seismic trace $\mathbf{d}_{j}$, columns $j$ of the matrix $\mathbf{D}$, can be obtained through the linear combination of eigenvectors associated with the temporal dimension. The weights used in the linear combination are the eigenvector coefficients associated with the spatial dimension scaled by the corresponding singular values. Another way to write the Eq. (1) is given below,

$$
\begin{aligned}
\mathbf{D} & =\left[\mathbf{u}_{1} \ldots \mathbf{u}_{N}\right]\left[\begin{array}{c}
\sigma_{1} \mathbf{v}_{1}^{T} \\
\vdots \\
\sigma_{N} \mathbf{v}_{N}^{T}
\end{array}\right] \\
& =\sigma_{1} \mathbf{u}_{1} \mathbf{v}_{1}^{T}+\cdots+\sigma_{N} \mathbf{u}_{N} \mathbf{v}_{N}^{T} \\
& =\widehat{\mathbf{D}}_{1}+\cdots+\widehat{\mathbf{D}}_{N} \\
& =\sum_{k=1}^{N} \sigma_{k} \mathbf{u}_{k} \mathbf{v}_{k}^{T}
\end{aligned}
$$

$\widehat{\mathbf{D}}_{k}=\sigma_{k} \mathbf{u}_{k} \mathbf{v}_{k}^{T}$ is matrix of unitary rank, also called eigenimage of the data matrix $\mathbf{D}$, whereas $\widehat{\mathbf{d}^{j}}{ }_{k}$ in the Eq. (3) is the trace $j$ of the eigenimage $\widehat{\mathbf{D}}_{k}$.

Equation (3) represents the SVD decomposition of a trace, while Eq. (4) represents the SVD decomposition of the entire image associated with the original data matrix. By limiting the summation in these equations we can obtain approximate representations of each seismic trace or of the whole image. Thus, the first singular values have a larger amplitude, making the associate eigenimages retain the features of higher spatial correlation (Freire, 1986). In this way the first eigenvectors are responsible for the reconstruction of the predominantly horizontal or subhorizontal events of greater amplitude. Porsani et al. (2009) used this method to emphasize horizontal and sub-horizontal events and to attenuate dip events associated with the ground-roll.

For each trace of a 2D seismic section or a 3D volume to be filtered, we can collect the subset of $N$ immediately neighboring traces, perform the SVD decomposition of the corresponding data matrix, and partially restore the trace $\widetilde{\mathbf{d}}_{j}$ through of the equation,

$$
\tilde{d}\left(t_{i}, x_{j}\right)=\sum_{k=1}^{K} \sigma_{k} u_{k}\left(t_{i}\right) v_{k}\left(x_{j}\right) .
$$

Thus, the trace $\tilde{d}\left(t_{i}, x_{j}\right)$ obtained from the first $K$ eigenvectors will represent the filtered trace. The small values of $K$ will be responsible for the generation of traces, sections and volumes of greater spatial coherence. SVD filtering can be seen as a multichannel filtering method where each filtered trace maintains a certain degree of coherence with immediately neighboring traces.

The proposed SVD filtering method consists of the systematic application of the Eq. (5) on all traces of a seismic line or a 3D volume, following the procedure:

- For each seismic trace (target trace) of the original seismic data;

- Select a subset of $N$ immediately neighboring traces and form the matrix $\mathbf{D}$;

- Perform the SVD decomposition of $\mathbf{D}$;

- Reconstruct partially the target trace using only the $K$ first eigenvalues.

\section{FX DECONVOLUTION}

In seismic data processing, the FX deconvolution is a random noise attenuation method in the spatial direction of the section using the complex version of the Wiener predictive filter (Gulunay, 1986). Thus, when the data are transformed from the time $\times$ distance domain to the frequency $\times$ distance, through the Fourier transform, a time-slice is now converted to a frequency-slice. Events with similar diving appear as a complex sine wave along a given frequency-slice. That is, they can be described in the form: $\cos (\omega t)+i \sin (\omega t)$. The FX deconvolution applied calculates a filter for each frequency, using a horizontal window of $N_{x}$ traces and number of time samples equals to $N_{t}$, in order to guarantee the coherence of the reflector.

Assigning the input section as $A(t, x)$, in the space-time domain, the process can be described by the following steps:

- Applies the Discrete Fourier Transform to each seismic trace;

- For each frequency $f$;

- Compute the autocorrelation;

- Obtain the complex prediction error operator; 
- Convolve the prediction operator with the data;

- Perform the inverse Fourier Transform.

This process produces an output with a lower random noise level when compared to the input data.

\section{NUMERICAL RESULTS}

The SVD filtering method was applied to synthetic data representing a marine 3D volume containing interesting structural features with a high degree of complexity. The SVD filtering, used in this work, is done on a subset of 5 neighboring traces of a seismic volume ( 5 traces spatial filter operator or cross operator), being the target trace to be filtered the the central trace of the filter operator. It is spatially displaced over the entire volume of data, and at each new position of the operator a SVD is performed and a new filtered trace is generated, and the result thus obtained represents the filtered seismic volume with the same dimension of the input data.

Figure 1 illustrates the operator applied in the filtering of a 3D volume of seismic data. Thus, the decomposition of the seismic data matrix into eigenimages can be applied in different stages of seismic data processing. And the proper choice of the number and indexes of eigenimages used in decomposition forms the basis of coherence filtering methods. Eigenimages are calculated based on the mathematical concept of linear algebra related to the eigenvectors and eigenvalues of the corresponding covariance matrices. This filtering technique is based on the idea that in order to extract the most correlated or coherent portion of the seismic data, we must use the eigenimages associated with the highest singular values.

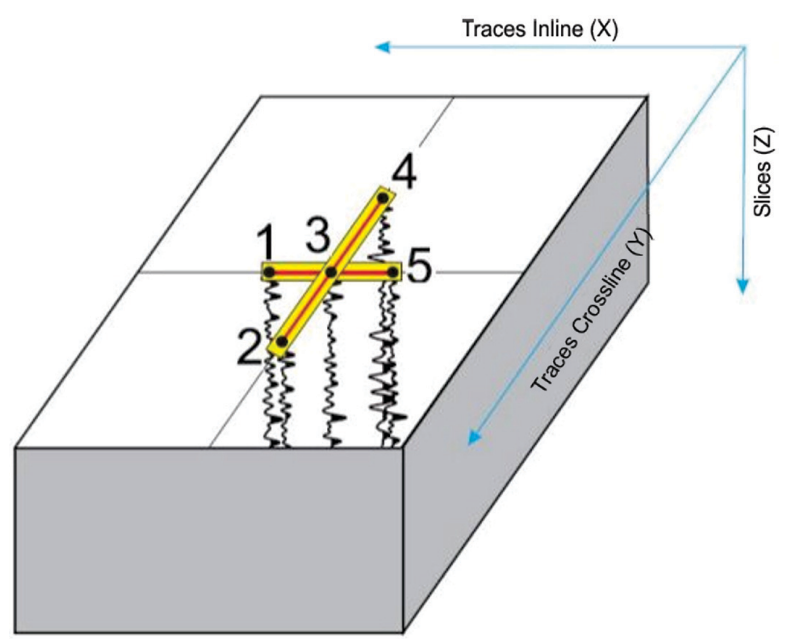

Figure 1 - Schematic representation of the 5 points operator extracting 5 adjacent traces of the 3D volume of seismic data (adapted from Porsani, 2010b).

\section{Marine Synthetic Data with Noise}

In this section we compare the efficiency between SVD and FX deconvolution methods when applied to a 3D seismic data for the purpose of attenuating random noise.

We have used a synthetic seismic data that simulates data from a sea survey and contains some interesting structural features that are usually present in real seismic data, such as salt domes, fault systems, folds, etc. We added to the 3D data volume the random noise with an $S / R$ ratio in the range of 0.5 of the maximum amplitude of the signal.

The comparative study between the methods, through the analysis of the images obtained before and after the application of the filtering, being presented in the form of seismic sections and time-slices, allowed us to evaluate how much the SVD filtering is within certain limits of applicability. It presents good results in regions of the volume where the structuring is smoother and with satisfactory results where the structural complexity is higher.

Figure 2 is a section in the XLINE direction, taken from the filtered 3D volume, where we can compare the response of the application of SVD filtering to that applied with the FX deconvolution. We can observe how much was removed from the random noise: a cleaner section with a higher signal-to-noise ratio and an evident improvement in the continuity of the reflectors, particularly the top of the body of salt located in the section between the times 3.2 and 3.9 seconds.

In Figure 3 we show another section in the XLINE direction, where it is possible to observe a better delimitation of the top and flank of the salt dome between times 1.6 and 2.2 seconds and the ILINES (371 and 550) respectively. It can also be observed in the lower left corner of the section, a greater value and continuity of the top of the salt layer, located between the ILINES (1 and 160) and the times 3.3 and 4 seconds, compared to the section after the application of the FX deconvolution method.

The time-slices in 1.5 and 2.5 seconds obtained with the application of the SVD filtering and FX deconvolution are illustrated in Figures 4 and 5 . The results presented by the methods are equivalent, and both limit the contours of the mini-basin. In some parts of the illustrated images, a small superiority of the SVD method is observed, as shown in Figure 6 where we can identify the existence of the salt wall between the XLINES intervals (XL: 100-150) and (XL: 250-320) after noise attenuation. Analyzing the five eigenimages and the partial sums between them, together with the graph of Figure 6 associated with the highest singular values, we came to the conclusion that the first eigenimage should be chosen to represent the filtered data. However, it was expected that the SVD operator would perform better where the events had horizontal or sub-horizontal behavior. 


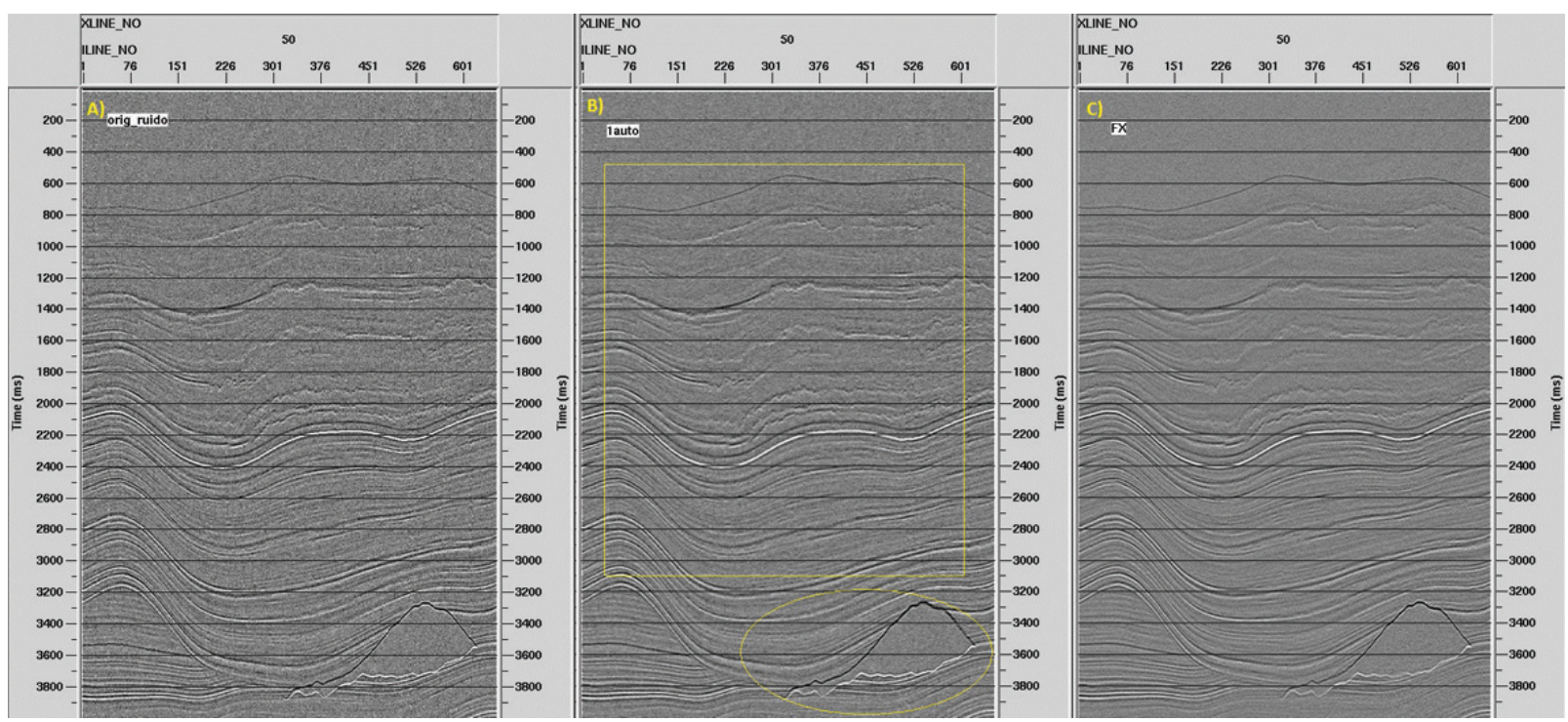

Figure 2 - Comparison between SVD and FX deconvolution. A) Original seismic section contaminated with noise, B) result of the SVD filtering and C) result of the FX deconvolution.

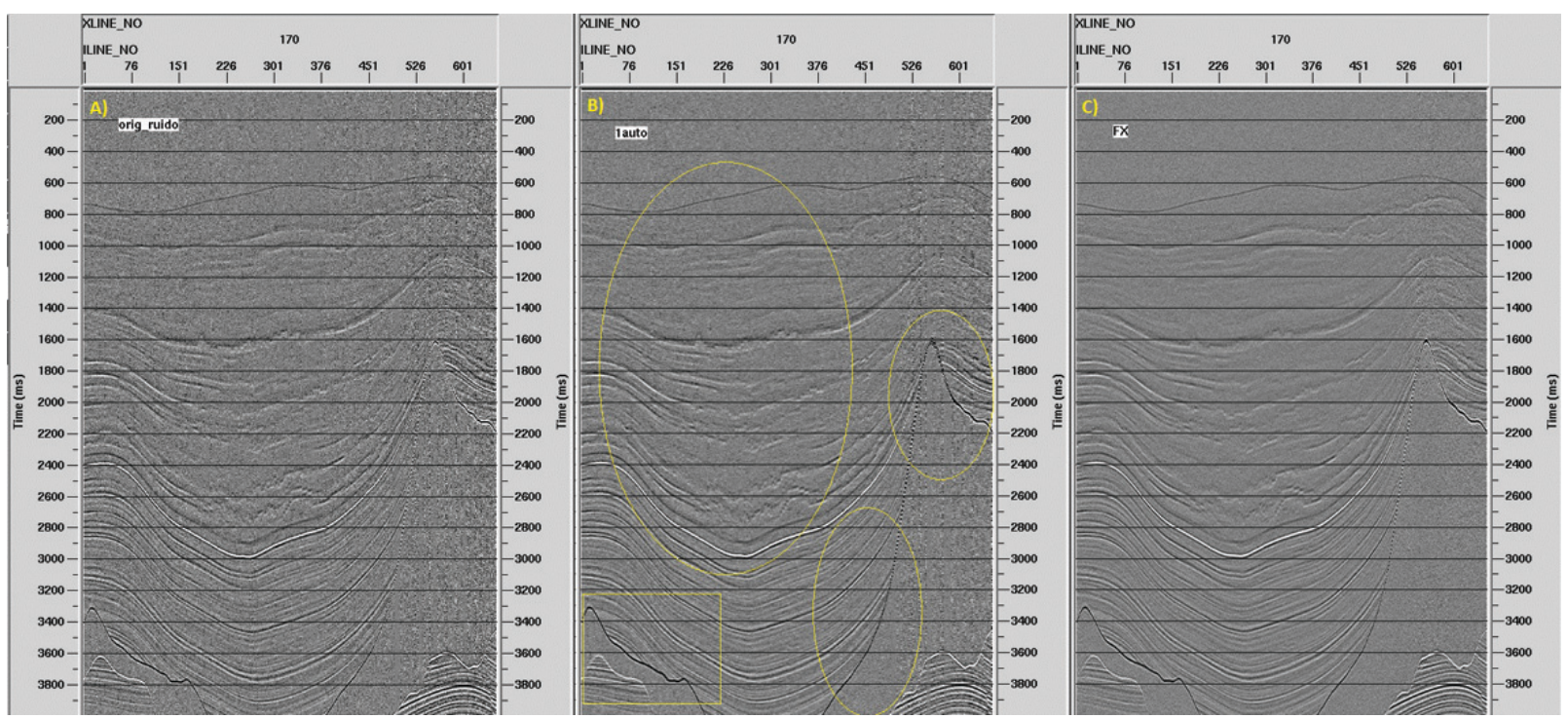

Figure 3 - Comparison between SVD and FX deconvolution. A) Original seismic section contaminated with noise, B) result of the SVD filtering and C) result of the FX deconvolution.

\section{Noise-free Marine Synthetic Data}

Assuming that the synthetic data without noise is equivalent to the representation of a migrated data with good quality, it does not make sense to apply the SVD technique for filtering, but to perform the decomposition with the purpose of highlighting the discontinuities usually associated with structural features of reality subsurface.

So we started looking for a new methodology that met our expectations, and decided to create a new seismic attribute similar to a cube of coherence. This new attribute represents a measure of the magnitude of the eigenimages, being defined as the sum of the square of the elements (sample of traces) that compose the matrix of each eigenimage $\mathbf{A}_{k}$, whose elements are $a_{k, i, j}$, where $k=1, \ldots, K$ (number of eigenimages); $i=1, \ldots, M$ (number of samples) and $j=1, \ldots, N$ (number of traces, $\mathrm{N}=5$ ), according to the following expression:

$$
d_{i j}=\sum_{k=1}^{K} \mathbf{a}_{k, i, j}^{2}
$$




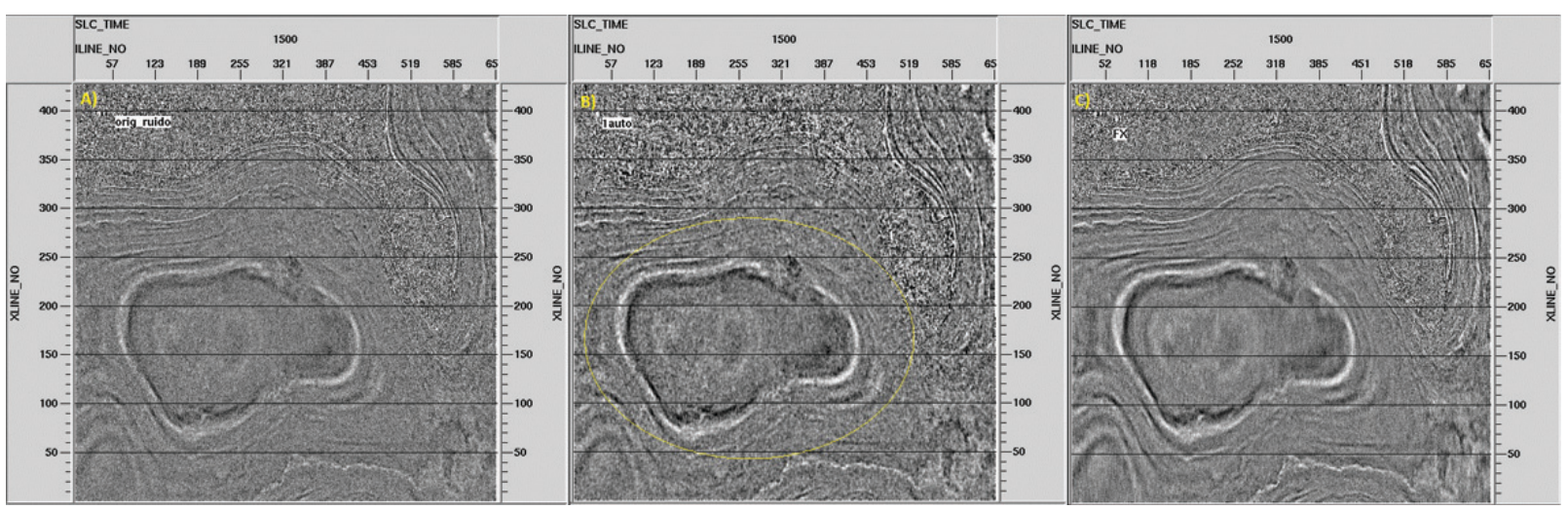

Figure 4 - Comparison between SVD filtering and FX deconvolution of time or time-slice in 1.5 seconds. A) Seismic data contaminated with noise, B) result of the SVD filtering and C) result of the FX deconvolution.

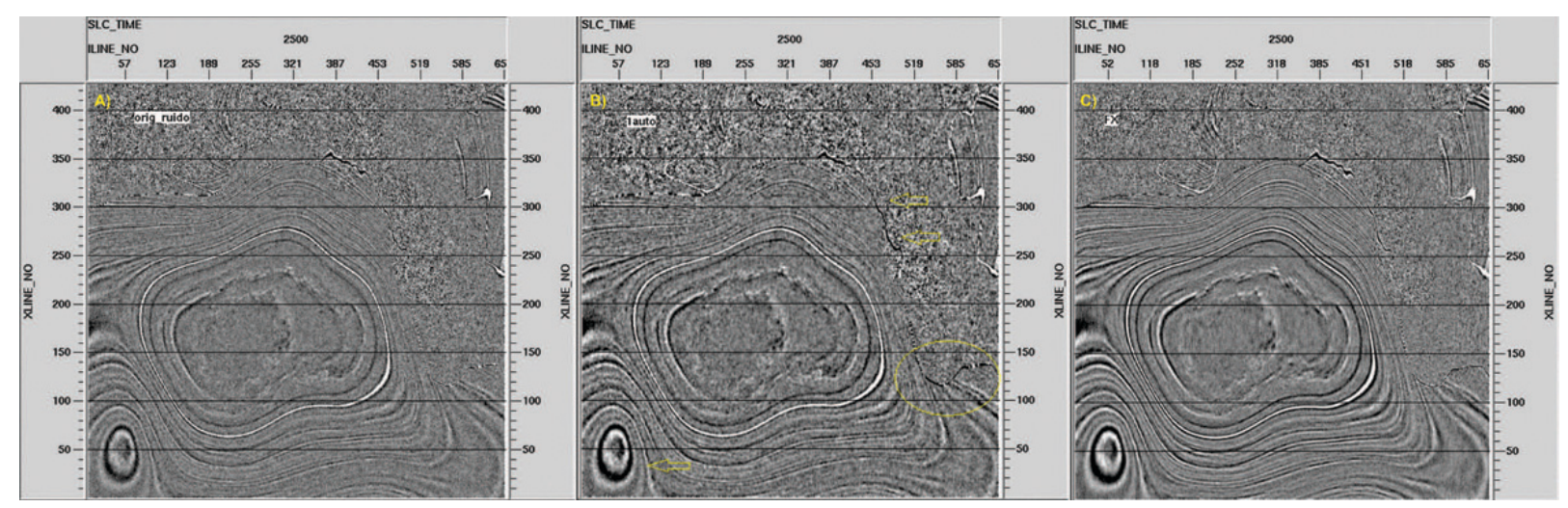

Figure 5 - Comparison between SVD filtering and FX deconvolution of time or time-slice in 2.5 seconds. A) seismic data contaminated with noise, B) result of the SVD filtering and $\mathrm{C}$ ) result of the FX deconvolution.

The test with the magnitude of the eigenimages provided encouraging results, for we have been able to create a seismic attribute equivalent to a coherence cube. We can observe from the Figures 7 and 8 by the analysis of the images in time-slices and sections, how this new methodology emphasized the discontinuities as fault planes, the flanks of domes, as well as the limits the limits of the mini-basin and folds of layers and improving the identification of the existing stratifications in the original data.

\section{CONCLUSIONS}

The SVD decomposition of the seismic volumes and the appropriate choice of the index and the number of eigenimages used in the reconstruction of the data matrix gave us good results in terms of filtering efficiency in order to suppress or minimize the random noise present in the data. From the analysis of the images in the form of sections and slices of time, after the application of the filtering, we clearly noticed the increase of the signal-to-noise ratio. Thus, we improve the continuity of the reflectors (spatial coherence) and their better identification and tracking, valuing the stratigraphic aspects of the seismic sections and volumes used here. However, when we want to highlight the discontinuities in order to set the limit and value structural features, it is not enough to simply decompose the data and choose the eigenimages or the truncated sum between them that can highlight the structures of interest. The attribute with the magnitude of the eigenimages had already proved to be a promising tool, since it allowed to highlight the discontinuities, thus valuing the structural features (fault planes, dome flanks, etc.) present in the data. The results presented here show that the SVD adaptive filtering method in 3D seismic volumes, associated with the attribute that measures the magnitude of the eigenimages, is effective and can reveal features and geological structures that were masked by the presence of additive noise to the data. In order to promote the improvement of the final image quality in the seismic section, this filtering technique can help the interpreter in the structural and 


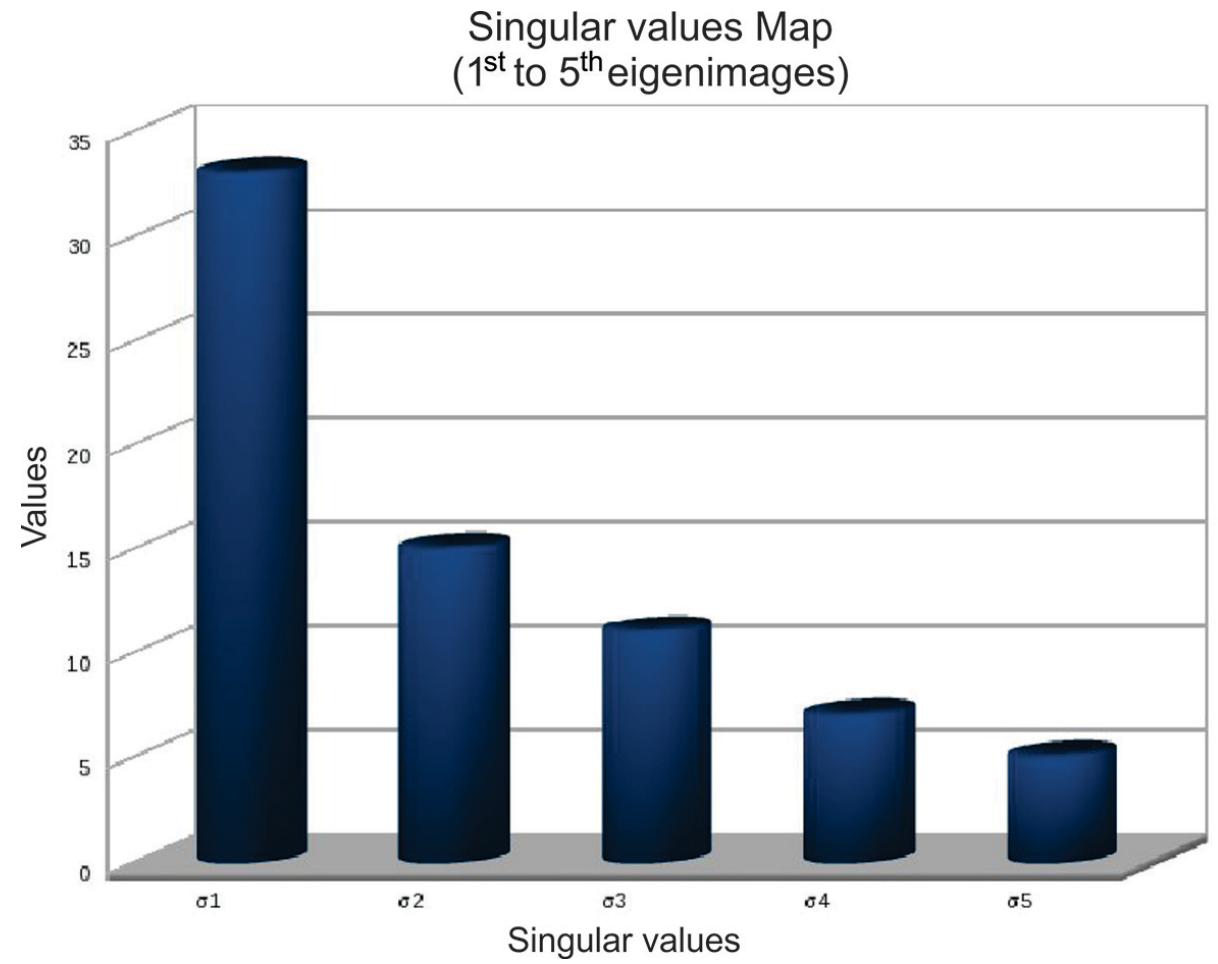

Figure 6 - Map of average singular values of the SVD decomposition of the marine 3D volume.
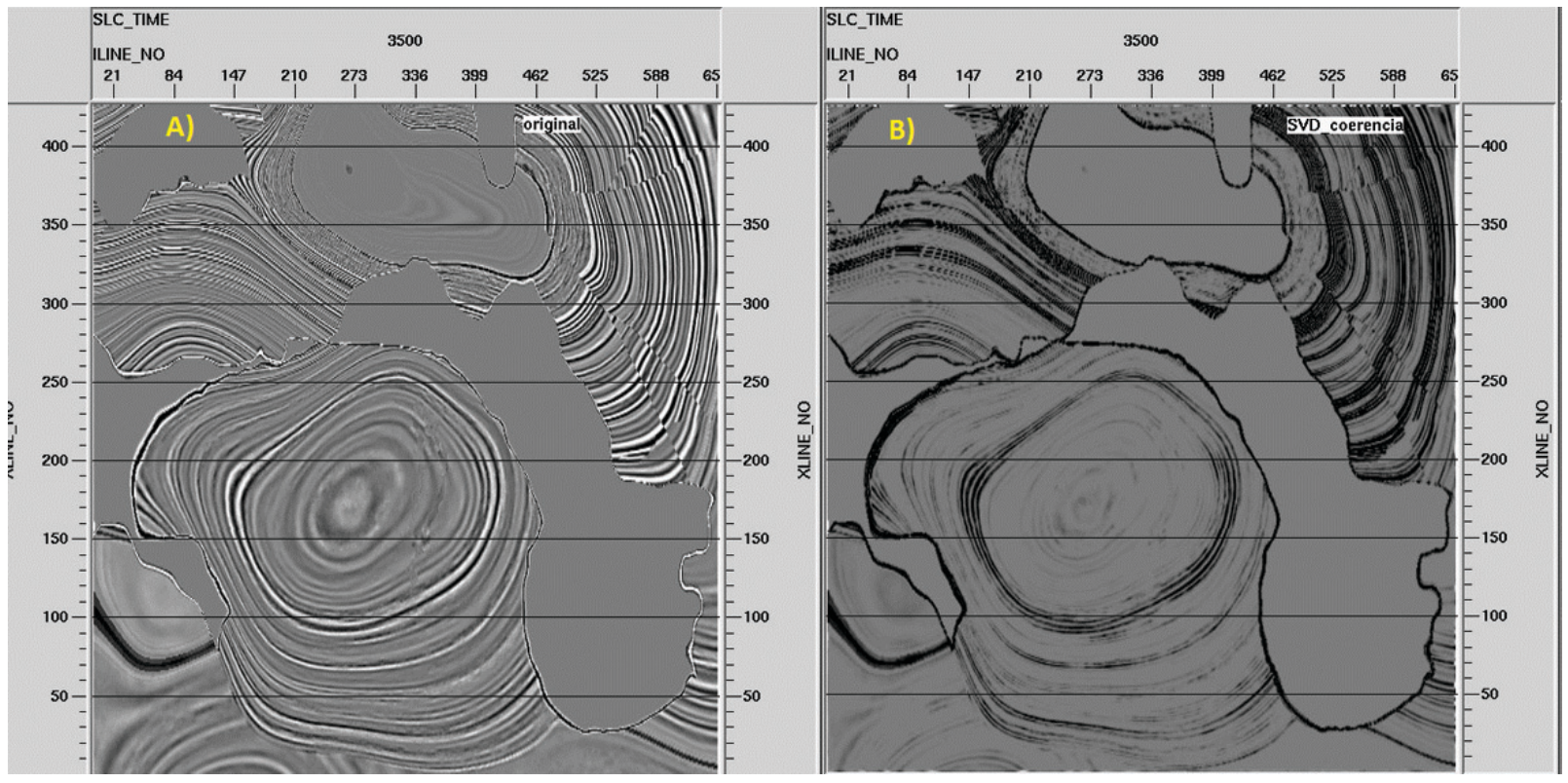

Figure 7 - Result of applying the SVD filtering approach to highlight structural features. A) Original data and B) Magnitude of SVD eigenimages.

especially stratigraphic analysis during the interpretative work of seismic sections and volumes in the search for and identification of possible wastes, promising targets for the accumulation of hydrocarbons.

\section{ACKNOWLEDGEMENTS}

The authors thank to INCT-GP/CNPq/MCT, ANP, PETROBRAS, FINEP, and FAPESB (Brazil) for financial support. 


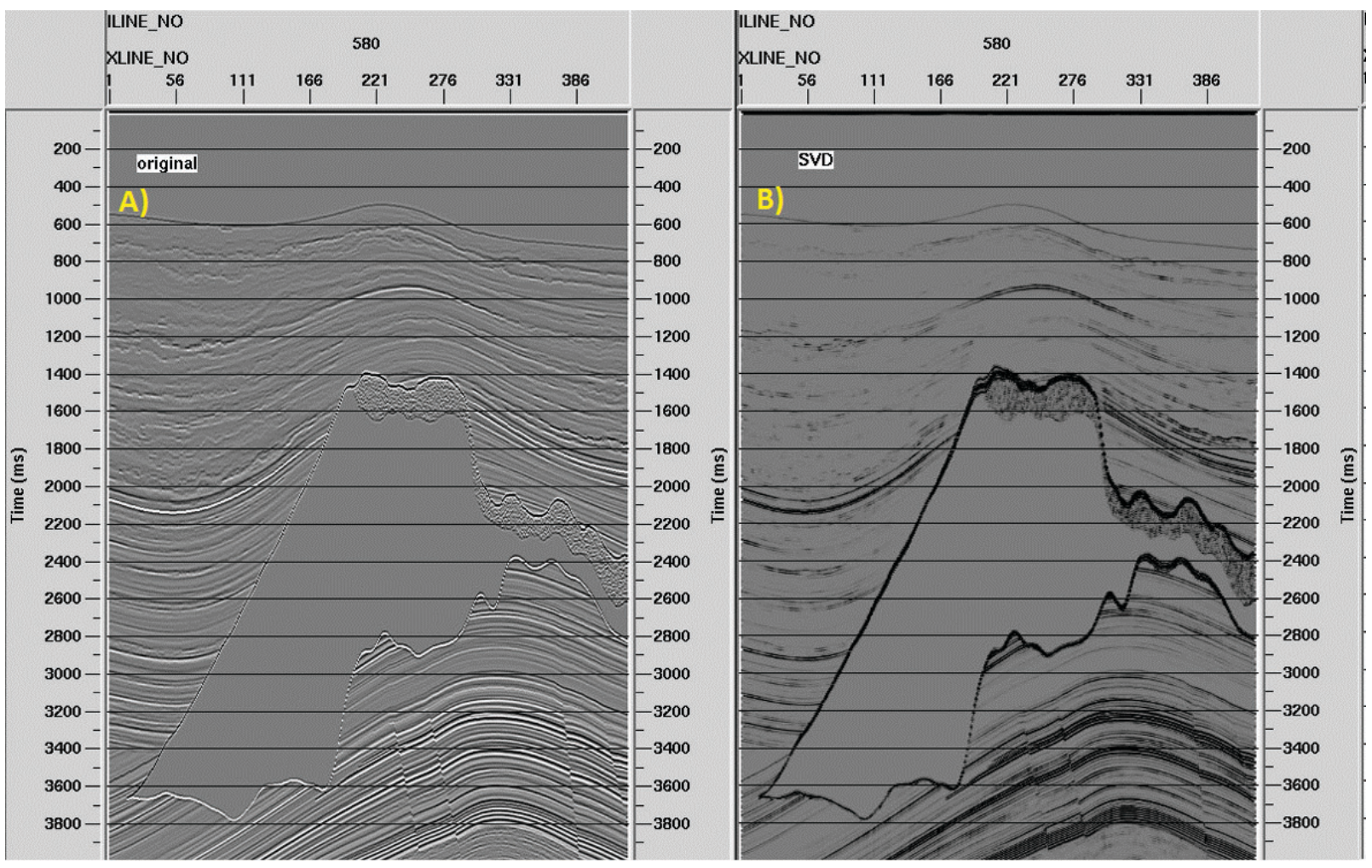

Figure 8 - Result of applying the SVD filtering to structural features. A) Original data and B) Magnitude of SVD eigenimages.

\section{REFERENCES}

BEKARA M \& BAAN MV. 2007. Local singular value decomposition for signal enhancement of seismic data. Geophysics, 72: V59-V65.

CHIU SK \& HOWELL JE. 2008. Attenuation of coherent noise using localized-adaptive eigenimage filter. In: Expanded Abstract, 78th Annual SEG Meeting, vol. 1, pp. 2541-2545, SEG.

FREIRE SLM. 1986. Aplicações do método de decomposicação em valores singulares no processamento de dados sísmicos. PhD thesis, Universidade Federal da Bahia - UFBA, Salvador, Brazil, pp. 181.

FREIRE SLM \& ULRYCH TJ. 1988. Application of singular value decomposition to vertical seismic profiling. Geophysics, 53: 778-785.

GOLUB GH \& VAN LOAN CF. 1996. Matrix Computations. Johns Hopkins University Press, Baltimore, 694 pp.

GULUNAY N. 1986. FXDECON and Complex Wiener Prediction Filter. In: 56th Annual International Meeting, Soc. of Expl. Geophys., 279-281.

KARSLI H \& BAYRAK Y. 2008. Ground-roll attenuation based on Wiener filtering and benefits of time-frequency imaging. The Leading Edge, 27: 206-209.
KENDALL R, JIN S \& RONEN S. 2005. An SVD-polarization filter for ground roll attenuation on multicomponent data. In: Expanded Abstract, 77th Annual SEG Meeting, vol. 1, pp. 928-932, SEG.

PORSANI MJ, SILVA MG, MELO PEM \& URSIN B. 2009. Ground-roll attenuation based on SVD filtering. In: Expanded Abstract, 79th Annual SEG Meeting, vol. 1, pp. 3381-3385, SEG.

PORSANI MJ, SILVA MG, MELO PEM \& URSIN B. 2010a. An adaptive local-slope SVD filtering approach to enhance events on seismic sections. In: Expanded Abstract, 80th Annual SEG Meeting, vol. 1, pp. 3717-3722, SEG.

PORSANI MJ, ARTOLA FAV, SILVA MG \& MELO PEM. 2010b. Filtragem SVD aplicada à melhoria do rastreamento de horizontes sísmicos. Brazilian Journal of Geophysics, 28: 473-480.

TYAPKIN YK, MARMALYEVSKYY NY \& GORNYAK ZV. 2003. Sourcegenerated noise attenuation using the singular valued decomposition. In: ExpandedAbstract, 75th Annual SEG Meeting, vol. 1, pp. 2044-2047, SEG. 